\title{
Sofrimento e trabalho na cidade em marcha forçada
}

\author{
Suffering and working in the city
} in forced march

Stela Cristina Godoi

\section{Resumo}

Para a história da cidade no século $\mathrm{XX}$, os trabalhadores metalúrgicos e os motoboys são uma voz arquetípica que retrata a mentalidade de uma época. A cidade vista sob a ótica desses dois grupos profissionais revela a brutalidade do processo de aceleração do tempo social. Assim, neste escrito, as memórias de metalúrgicos do $A B C$ paulista de meados do século $X X$ e os relatos orais de motoboys da Região Metropolitana de Campinas, coletados em duas pesquisas distintas, enlaçam-se em um processo de "escovação da história do sistema de circulação da cidade a contrapelo".

Palavras-chave: cidade; trabalho; violência; automóveis; tempo.

\section{Abstract}

For the history of the city in the 20th century, metallurgic workers and motorcycle couriers (known as "motoboys" in Brazil) are somehow an archetypal voice that portrays the mentality of an entire era. The city viewed in the perspective of these two social-professional groups reveals the brutality of the acceleration process of social time. Thus, in the lines below, the collective memoirs of metallurgic workers of São Paulo's $A B C D$ industrial belt in the mid-twentieth century and the oral autobiographical reports of "motoboys" in the Metropolitan Region of Campinas, collected in two separate surveys, intertwine in a process of brushing the history of the city's circulation system against the grain.

Keywords: city; labor; violence; cars; time. 


\section{Introdução}

A cidade é "como a lâmpada para a mariposa. Atrai e também mata", assim afirmou o finado Philadelpho Brás, metalúrgico, sindicalista e memorialista da classe operária paulista, em tom carregado de sabedoria anciã. Por meio da licença poética concedida aos narradores, Philadelpho suscita uma reflexão sobre o caráter contraditório das relações sociais formadoras da cidade. À cidade associa-se a imagem da iluminação, à ideia de iluminação, associa-se a de modernidade. As luzes da cidade como fator de atração a revoadas de migrantes, de mariposas, entre a vida e a morte. Essas mariposas são o Carlitos de Charles Chaplin. Esse "herói solitário e triste" vagando pelo "deserto povoado pela multidão" em que se constitui a cidade (lanni, 1989). São o homem da multidão de Edgar Alan Poe, o flâneur de Charles Baudelaire ou, ainda, o Mazzaropi, anti-herói caipira da autêntica modernidade brasileira.

Mas a cidade não é uma abstração e, enquanto espaço de interação social, só ganha concretude histórica se associada à categoria temporal e se concebida dentro de um sistema social de produção e reprodução da vida. Desse modo, este escrito buscará promover uma reflexão sobre as mudanças na forma de ser-estar da cidade no bojo do desenvolvimento da indústria automotiva no Brasil, tomando o caso da Região Metropolitana de São Paulo (RMSP) e da Região Metropolitana de Campinas (RMC) como base empírica dessa análise. Pretende-se, ademais, pensar a cidade como espaço simbólico do mundo moderno, o que torna necessário levar em consideração as metamorfoses da própria ideia de modernidade no interior da processualidade histórica do capitalismo.
No século XIX, Paris era considerada a capital da modernidade e, nessa condição, exerceu grande influência sobre a configuração da vida citadina na RMSP e na RMC. Em meados do século XIX, com as reformas empreendidas pelo prefeito do Departamento de Sena, George-Eugène, o Barão de Haussmann, a cidade de Paris materializou as aspirações iluministas. ${ }^{1}$ Água, esgoto e gás encanados para evitar epidemias que tinham vitimado centenas de pessoas na primeira metade do século. Incontáveis desapropriações e demolições dos casarios para dar lugar às ruas largas e bem calçadas, aos bulevares e dezenas de novas edificações padronizadas, para evitar motins e barricadas, que num passado recente haviam ocupado o enredado das vielas e das ruas estreitas que caracterizavam a topografia do centro de Paris (Benjamin, s/d).

Por sua vez, toda essa nova arquitetura parisiense havia sido inspirada no modelo londrino de urbanização, que estava à frente de toda a Europa na modernização da cidade, sobretudo pelo seu sistema de circulação urbano que, desde o século XVI, já chamava a atenção pela rede de vias fluviais, ferroviárias e rodoviárias que contribuíram para que Londres se tornasse o centro do mercado mundial (Wood, 2000). ${ }^{2}$

Entretanto, com as destruições promovidas pelas duas guerras mundiais no território europeu e o fortalecimento político-econômico e militar dos Estados Unidos da América, a partir de meados do século $\mathrm{XX}$, a própria ideia de modernidade se metamorfoseia em resposta aos novos interesses de transnacionalização da indústria capitalista taylorista-fordista. Portanto, no contexto de hegemonia norte-americana, as cidades, sobretudo aqueles matizadas 
pela dominação colonial, vivem uma nova onda de modernização que repercutiu na maior adequação de seus espaços de circulação para a espetacularização do consumo de automóveis. Ou seja, rodovias, grandes avenidas, mais estacionamentos públicos e privados, tudo para assegurar a livre circulação dessa mercadoria-símbolo da modernização capitalista no mundo subdesenvolvido. Assim, no Brasil, em meados do século $X X$, os bondes e os trens foram parando de prestar seu serviço no transporte de pessoas e foram sendo substituídos pelos ônibus, caminhos, carros e, mais tarde, pelas motocicletas.

Nesse sentido, para se compreender a transformação pela qual passam as cidades brasileiras e o modo de vida urbano no bojo do processo em que a indústria automotiva foi conquistando papel central no projeto de desenvolvimento nacional, é preciso levar em consideração a importância desses espaços de circulação para a economia capitalista. $\mathrm{Na}$ medida em que a reprodução social desse sistema societal depende da realização da mais-valia através da distribuição, troca e consumo de mercadorias, as cidades tornaram-se o nervo essencial de uma economia cada vez mais capitalista e monetarizada, justamente porque abrigaram as atividades ligadas à circulação de bens e, consequentemente, ligadas à circulação de excedente (Santos, 1979).

A década de 1960 é marco temporal importante também para as cidades europeias. Com Harvey (2014) podemos asseverar que um novo cenário urbano reflete não só mudanças geopolíticas na divisão internacional do trabaIho, como também micropolíticas. A imagem estampada em cartaz na década de 1960, de uma "retroescavadeira devorando vorazmente todos os antigos bairros de Paris", representa um sentimento de que a cidade antiga "não podia mais permanecer como era, mas a nova parecia demasiado horrível, sem alma e vazia para se contemplar" (ibid., p. 10).

Todavia, o processo de racionalização capitalista não poupou essa cidade industrial, ela também foi sendo transformada, ao final do século XX, na "cidade-mercadoria" marcada por uma segregação de classes ainda maior. Por trás dos muros dos condomínios fechados e das novas barricadas urbanas dos territórios do crime, a produção do espaço urbano, a partir da década de 1990, encarna a face bipolar do ódio e da indiferença blasé ao outro (Caldeiras, 2000). Ademais, a reestruturação produtiva do capital promoveu uma mudança profunda no mundo do trabalho e nas referências que pautavam e ritmavam a vida social. Amplia-se uma desconexão entre trabalho e empresa, tempo de trabalho e tempo de não trabalho, formal e informal, emprego e moradia. Nesse sentido, a produção do espaço urbano é também a produção de determinados percursos instáveis e desiguais dos sujeitos pelo mundo do trabalho precário e global das prestadoras de serviço terceirizadas, dos vendedores ambulantes, das empresas globais num mercado de consumo cada vez mais sedutor (Telles, 2006).

Assim, para pensarmos a violência implicada no processo de compressão do tempo-espaço que define a produção do espaço urbano, buscamos compreender essa nova tessitura entre trabalho e cidade através do aporte de uma perspectiva epistemológica que historicize a cidade a partir da experiência e da memória da "gente comum", 3 pois, quando pensamos a transformação da cidade, não basta fazer uma genealogia das ideias daqueles que, no mundo 
acadêmico, tentam compreender o processo. É preciso levar em consideração o

[...] papel desempenhado pela sensibilidade que surge das ruas que nos cercam, pelos inevitáveis sentimentos de perda provocados pelas demolições, [...], ou 0 desespero que provém do sombrio desespero da marginalização e da juventude ociosa perdida no puro tédio do aumento do desemprego. (Harvey, 2014, p. 12)

Promovendo nexos entre o passado, 0 presente e o futuro, Walter Benjamin apresenta uma perspectiva histórica dialética que permite analisar essas metamorfoses da cidade ao longo do desenvolvimento capitalista, de modo que a nostalgia do passado se constitua no método revolucionário de crítica do presente (Löwy, 2005). Dialogando com os historicistas, refletindo sob o contexto histórico do fascismo, Benjamin (1994) ensaia, nas teses "Sobre o conceito de História", outro conceito de história, mediante o qual sejam desnudadas as ameaças - promovidas pelo contínuo processo de modernização capitalista - que o progresso técnico e econômico faz pesar sobre a humanidade: a transformação dos seres humanos em máquinas de trabalho, a degradação do trabalho a uma simples técnica, a submissão desesperadora das pessoas ao mecanismo social. Nesse sentido, Benjamin (1994) alerta para a necessidade de que a história seja vasculhada a contrapelo. Segundo esse autor, partindo do princípio filosófico de que não há luta pelo futuro sem memória do passado, "escovar a história a contrapelo" significa a recusa em se juntar ao cortejo triunfal dos vencedores e possibilita um salto para fora da marcha do progresso.

Num sentido similar, Thompson contribui com esse esforço de análise histórica na contramão da marcha do progresso com uma chave heurística fundamental que foi pensar a atuação dos sujeitos no processo histórico. Thompson (1981), criticando o estruturalismo althusseriano, propôs a inclusão de um termo ausente no sistema conceptual anterior: "a experiência". Naquele sistema, a determinação e a autonomia aparecem como as duas pontas de uma mesma cadeia; enquanto, para Marx, segundo Thompson (ibid.), determinação e autonomia são as duas formas de dizer a mesma coisa. Assim, através dessa outra concepção proposta por Thompson, não se compreende a realidade histórico-social como um encadeamento mecanicista, mas sim como um processo histórico aberto.

Desse modo, tomando de empréstimo essas reflexões de Benjamin e Thompson, neste escrito, propõe-se olhar a cidade, bem como seus espaços de circulação e formas de sociabilidade, partindo das memórias e das experiências do conjunto de entrevistados dos dois estudos desenvolvidos pela pesquisadora, sobre os metalúrgicos do $A B C$ de meados do século $\mathrm{XX}^{4}$ e sobre os motofretistas que atuam hoje em Campinas, ${ }^{5}$ com vistas a realizar um processo de reconstrução da história do desenvolvimento urbano paulista a contrapelo.

\section{A transformação do transporte urbano no bojo do desenvolvimento capitalista}

No Brasil do final do século XIX e primeira metade do século $X X$, a ferrovia puxou a expansão da cafeicultura. Na capital paulista, via-se surgir a cada dia uma novidade diferente: 
a eletricidade substituía o lampião a gás, chegavam os primeiros carros, cresciam as linhas de bondes elétricos e construíam-se grandes obras urbanas. Segundo Martins (2004), essas passagens simbolizam transformações sociais importantes, já a sociabilidade produzida pelo uso do bonde e do trem continha traços de uma sociedade tradicional em franca modernização:

0 bonde junta 0 que na sociedade tradicional não se juntava: o homem e a muIher desconhecidos, o padre e o protestante antagônicos. As pessoas se tocam, se encostam, empurradas no movimento incontrolável da máquina, da coisa, que simboliza o que a Cidade é. Ela tem força própria, dita o lugar das pessoas, quebra as regras, tumultua, confunde. (p. 203)

A viagem de trem, tal como a de bonde, aparece viva na memória da maior parte dos trabalhadores que viveu em meados do século XX. De acordo com Certeau (1994), a viagem de trem expressava simbolicamente a experiência da vida moderna. 0 trem corta o espaço; a vidraça permite ver e os trilhos atravessar. 0 vagão alia o sonho à técnica e mergulha o viajante na melancolia de ver aquilo de que está separado (ibid.). Conforme mostra o relato de Philadelpho, a máquina parada parece monumental, um ídolo mudo:

Passava um trem de manhã, outro trem de noite. De noite vinha para São Paulo. Então [...] para gente que estava com uns treze anos [...], ver aquelas Marias-Fumaças cheias de metais brilhantes, aquele condutor, o chefe da máquina fardado que parecia um general, era um encanto para alma da gente. Aquele vagão, restaurante que só dava fazendeiro, gente rica. Claro que a gente era pobre, estava lá na gaiola. Viajar de trem, embora a Mogiana não era a melhor [...], aquilo foi a maior aventura de criança para mim [...]. (Philadelpho, metalúrgico, 2006)

Assim, é interessante observar acerca das memórias narradas pelos metalúrgicos aposentados da RMSP que, ao mesmo tempo que, no olhar do presente, o trem e o bonde fazem parte de uma sociedade tradicional que remete a um passado pré-moderno, eles compõem também o quadro social da modernidade no Brasil. 0 estudo de memória desenvolvido por Hadler (2007) sobre a história dos bondes de Campinas também se depara com o mesmo paradoxo. A análise de dois momentos do discurso ideológico da modernidade, no início e em meados do século $X X$, permite compreender que se a substituição do bonde à tração animal pelo bonde elétrico foi vista, pela ideologia liberal do período, como um avanço na construção de sua modernidade. Sob o contexto mundial de hegemonia norte-americana, esse mesmo bonde elétrico que, há cerca de três décadas, era idolatrado como símbolo de elegância e modernidade pelas elites da cidade, passa a simbolizar o seu atraso (ibid.).

Essa transição no sistema de transporte brasileiro pode ser observada também ao se analisar a evolução das redes férreas e rodoviárias ao longo do tempo. De modo geral, as estatísticas históricas do IBGE mostram que, a partir da última década do século XIX e início do XX, a malha ferroviária brasileira deu o seu primeiro grande salto, crescendo em quilômetros continuamente até 1970, quando o País veio a perder $16 \%$ da rede ferroviária que tinha uma década antes. Ao longo desse período, os estados de Minas Gerais e São Paulo destacaram-se com as redes mais extensas de ferrovias 
em tráfego, diminuindo em extensão na mesma década em que há um declínio em todo o território nacional.

Considerando a evolução da extensão da rede rodoviária ao longo do tempo, as estatísticas históricas do IBGE mostram que houve um crescimento contínuo da rede rodoviária do País desde 1954, quando contava com 302.147 km de extensão. Entretanto, foram nos anos de 1965 e 1967 que o salto foi maior, iniciando a década de 1970 com mais de um milhão de quilômetros de via de rodagem, uma extensão quase quatro vezes maior do que a totalidade da rede férrea naquele período. Essa mudança na estrutura do transporte no Brasil, em certa medida, está relacionada com a própria característica do transporte ferroviário, o qual, de acordo com Kurz (1996), trazia, do ponto de vista capitalista, uma imperfeição:

Não no sentido tecnológico, mas, de modo mais fundamental, no sentido econômico e, de certa maneira, até espiritual. [...] Enfim, a ferrovia, do ponto de vista capitalista, possui uma mácula irrecuperável: a de ser necessariamente [...] um"bem público". [...] A ferrovia é, a longo prazo, incompatível com o capitalismo, tanto em seu aspecto espiritual-intelectual, como no seu aspecto econômico". (Ibid., p. 3)

Entretanto, não se trata apenas de explicar o favorecimento dado ao transporte rodoviário no desenvolvimento capitalista no Brasil somente pelo caráter público das ferrovias, uma vez que é sabido que países europeus totalmente mergulhados nas determinações do capital continuam até hoje a utilizar amplamente o sistema ferroviário de transporte. Ou seja, tratou-se, sobretudo, de um projeto de desenvolvimento dependente que aqui se configurou.

Assim, em virtude do projeto de desenvolvimento nacional-desenvolvimentista, de caráter dependente, definido a partir da década de 1950 no contexto de hegemonia norte-americana do pós-Segunda Guerra Mundial, as cidades brasileiras se transformaram em verdadeiras passarelas para o desfile dessa mercadoria-símbolo da modernização capitalista na periferia do sistema.

Portanto, embora desde o final da Primeira Guerra Mundial já viesse se dando a implantação dessa indústria, foi, a partir do governo Juscelino Kubitschek (1956-1961), que ela passou a ter um papel de grande destaque no desenvolvimento nacional. 0 automóvel entra na história do desenvolvimento urbano-industrial brasileiro como o principal símbolo da concepção de modernidade que prevalecia em meados do século XX.

A vinda das montadoras de automóveis para o Brasil, organizadas dentro do padrão internacional de produção taylorista-fordista, atendia aos interesses das próprias corporações norte-americanas e europeias, em seus planos de transnacionalização no pós-1945. Portanto, ao final do governo JK, já existiam instaladas no País cerca de nove montadoras: Ford, General Motors, International Harvester, Mercedes-Benz, Scania-Vabis, Simca, Vemag, Volkswagen, Willys-Overland, dentre outras.

A respeito dessa enorme influência, econômica e ideológica, exercida por essas montadoras no desenvolvimento capitalista do século XX no Brasil, vale a pena sublinhar que, a despeito de seu caráter hegemônico, o olhar de um metalúrgico que viveu esse contexto histórico mostra as fissuras dessa ideologia: 
Acabaram com as nossas ferrovias para por um produto das multinacionais na estrada [...] Eu acho que no futuro [...] haverá um choque muito grande, viu! Primeiro eu falo, puxa, onde é que vamos por tanta sucata?! Hoje você passa por aí, em qualquer lugar, nessas cidades grandes, o cara está derrubando uma casa antiga, para quê? Para fazer estacionamento. Você sabe que 0 automóvel[...] é um ícone nos países subdesenvolvidos. Então aqui, o cara só não leva o automóvel para dormir com ele, porque a mulher briga, né! [...] Então, automóveis todo mundo fabrica, no mundo inteiro fabrica, eu quero ver o que vai fazer, vai comer automóvel? Eu falo: "se vai comer automóvel começa pelo pneu e pelo estofamento que é mais mole!" . (Philadelpho, metalúrgico, 2006)

Mas, a despeito desses discursos contra-hegemônicos, a trajetória de crescimento da indústria automotiva no Brasil, definindo os rumos do desenvolvimento econômico nacional, manteve-se firme até 1980, quando o quadro econômico de estagflação (estagnação da produção com inflação) e endividamento externo, agravado pelo cenário internacional de recessão econômica e social, colocou obstáculo a essa tendência de expansão de vendas dessas corporações no mercado interno. Desse modo, os fabricantes de veículos e autopeças aqui instalados buscaram intensificar a exportação, em um contexto mundial de transformações produtivas, que impactaram em exigências de preço, qualidade e entregas internacionais (Pinto, 2006).

Tais transformações, por sua vez, constituíram-se na resposta do capital diante de sua crise estrutural, instaurada a partir dos choques do petróleo de 1973 e 1979, e deviam-se, em partes, à saturação da norma social de consumo, já que o mercado de bens duráveis, como automóveis e eletrodomésticos, que sustentou a expansão econômica do capitalismo industrial até meados do século $X X$, havia se saturado nas décadas de 1960 e 1970.

Nesse sentido, embora a década de 1980 possa ser considerada um marco do relativo recrudescimento da trajetória francamente expansiva da indústria automotiva no Brasil, não se pode afirmar que tal frenagem na produção e no escoamento interno da mercadoria-símbolo da modernidade capitalista tenha levado a uma mudança mais significativa do enfoque do sistema de circulação brasileiro, centrado no transporte rodoviário. Ao contrário, a frota de veículos continuou crescendo em todo o País.

0 estado de São Paulo tem atualmente a maior concentração de automóveis, caminhões, ônibus e motocicletas do País. Uma frota de veículos cerca de 10 vezes maior do que a de estados grandes e populosos, como o Rio de Janeiro, conforme apontam os dados fornecidos pelo IBGE-estados referente a 2010. Por sua vez, é ainda mais alarmante o poder de mercado da indústria automotiva e de todo seu ideário individualizante, que predomina nas grandes cidades paulistas: o fato de que a cidade de São Paulo sozinha tem uma concentração de automóveis maior do que o Estado inteiro do Rio de Janeiro ou do Paraná.

Portanto, desdobramento do próprio crescimento do transporte privado e individualizado de automóveis são os congestionamentos e o aumento da frota de motocicletas. No estado de São Paulo a frota de motos é de 3.322.544 unidades. Destas, cerca de 20\% se concentram na capital e $3 \%$ em Campinas (89.011 unidades). 
Ou seja, paradoxalmente à resposta dada pelo empresariado diante da crise estrutural do capital - ao reestruturar o padrão de produção taylorista-fordista sob influência do ideário toyotista, visando à uma aceleração do tempo de giro do capita ${ }^{6}$-, o consumo em massa de veículos impôs limites à realização dessa necessidade de maior velocidade-mobilidade, na medida em que os frequentes engarrafamentos de veículos tornaram o "automóvel" um "autoestático" (Kurz, 1996).

Desse modo, essa dinâmica contraditória do padrão produtivo que Kurz (ibid.) chamou de "capitalismo automobilístico" produziu não uma superação dessa norma social de consumo de automóveis, mas sim uma nova demanda para o mercado de motocicletas, instaurando uma vivência de mobilidade urbana extremamente conflituosa, em que carros, ônibus, caminhões, vans e motocicletas disputam um espaço.

Embora, desde fins da década de 1960, já existissem alguns modelos de veículos de duas rodas em circulação, tal como as lambretas, foi, a partir da década de 1980 e, sobretudo 1990, que a frota de motocicletas cresceu aceleradamente. De acordo com os dados do Mapa da Violência de 2011 sobre o crescimento da frota de veículos na década 1998-2008, nesses anos a frota total do País cresceu uma média de $8,4 \%$ a.a., enquanto a frota de automóveis cresceu em média 6,5\% a.a. e a de motocicletas, por sua vez, cresceu em média 17,2\% a.a., mais do que a média geral.

Ou seja, não só o trânsito se tornou mais sobrecarregado por conta do maior número de veículos de todos os tipos que passou a circular, como a tendência de distribuição da frota se inverteu. Enquanto os automóveis, que no início desse período analisado representava $70 \%$ da frota total, passou a 58,8\% em 2008, as motos, que representavam $11,5 \%$, subiu a $24,0 \%$, aumentando sua representação no conjunto de veículos em circulação.

Alguns fatores interferiram para essa mudança de cenário do trânsito. Além do processo de "compressão tempo-espacial" que se acirra na década de 1990, em resposta à crise estrutural do capital, tornando as motocicletas uma opção de transporte mais interessante pelo seu menor custo e maior agilidade, outro fator de estímulo para a massificação de seu uso, a partir dessa década, foi a instalação de indústrias de ciclomotores no País.

Desse modo, no conjunto das grandes corporações que contribuíram para o desenho da rede de transporte que se tem hoje no Brasil, estruturando noções de organização eficiente do espaço e aceleração do tempo, a Honda teve liderança desde sua instalação no País, em 1971, apresentando hoje uma dominância de cerca de 90\% do mercado brasileiro. A Honda soube explorar de modo exemplar, por meio do slogan "Asas da liberdade!", o desejo frustrado de liberdade substantiva de que o indivíduo moderno padece, sobretudo no contexto em que o seu direito liberal de ir e vir é questionando pelo caos urbano gerado pelas operações logísticas just in time.

Desde o início da crise estrutural do capital e da reestruturação produtiva, passou-se a operar uma transformação qualitativa do complexo produção-circulação de mercadorias. As cidades, antes meros espaços de circulação apartados da produção direta de mais-valia, transformaram-se em extensões da indústria taylorista-fordista toyotizada. A lógica do just in time externalizou os estoques das "fábricas 
enxutas" para as ruas da "cidade fabricalizada", saturando a cidade de caminhões e motocicletas obstinados em assegurar o fluxo de mercadorias e informações, ao mesmo tempo que continuou a gerar incessantemente a necessidade do consumo de meios de transporte individualizados, que permitissem a completa sincronização de toda a população a esse tempo certo (Ferrari, 2012).

Assim, levando em consideração essa complexificação da frota urbana de veículos, buscar-se-á desenvolver, a seguir, uma reflexão sobre as repercussões dessas transformações na estrutura do transporte sobre a forma de sociabilidade nos espaços de circulação da cidade, partindo da prerrogativa de que a experiência dos motofretistas, categoria de trabalhadores caricatos do padrão just in time de produção, fornece pistas importantes sobre o modo de ser da sociedade contemporânea.

\section{Violência no trânsito e expropriação do tempo na "cidade fabricalizada"}

Demolições, alargamento das ruas, construção de shoppings e de estacionamentos fazem parte da memória coletiva daqueles trabalhadores da cidade industrial que assistiram à transformação da cidade como a sua própria ruína. Seus relatos sobre a metamorfose da São Paulo cortada pelas ferrovias à "capital do automóvel" se estruturaram pela vivência do desemprego de seus filhos e netos. Assim, a "cidade-mercadoria", que emerge com a globalização, aparece, na memória dos trabalhadores industriais de meados do século $X X$, como um "outro", que não conseguem mais reconhecer. A "cidade-mercadoria" surge como crise.

Desse modo, conforme afirma Telles (2006), na produção do espaço urbano da "cidade-mercadoria" que emerge com a globalização, o outro lado da "cidade de muros" não é a suposta (e falsa) democratização da "nova sociedade do consumo". A questão é outra:

[...] Pois nesses tempos de globalização, seguindo os movimentos acelerados de desterritorialização do capital, a riqueza social mobiliza os "artefatos urbanos", [...] no mesmo passo em que se vai ampliando a inadimplência generalizada. Qualquer um que circule pelos bairros das periferias mais pobres haverá de encontrar a parafernália do consumo moderno e pós-moderno, e haverá de encontrar 0 morador pobre desses lugares mais-doque-pobres exibindo, junto com a fatura de uma dívida sempre adiada, as versões populares (ou nem tanto) dos cartões de crédito que também chegaram por lá: é a financeirização do popular fiado. (Telles, 2006, p. 6)

Assim, como nunca, na atual conjuntura da organização socioeconômica capitalista, a cidade caracteriza-se pela subordinação do espaço pelo tempo e pela reificação das relações sociais que coisifica os homens e humaniza as coisas (Ferrari, 2012).

Tal conjuntura produz uma interação profundamente hostil entre os condutores de veículos, pedestres e ciclistas que dividem o espaço das vias públicas, a qual repercute diretamente sobre os motofretistas que trabalham nesse espaço antes improdutivo para o capital, os espaços de circulação da cidade, para onde a produção capitalista se transborda na contemporaneidade. 
Assim, os inúmeros relatos coletados durante o trabalho de campo da pesquisa, narrando episódios de desentendimento entre motofretistas, caminhoneiros e motoristas de ônibus e carros em Campinas, apontam para essas situações de conflito no trânsito que fazem parte de uma condição de trabalho permanente na vida desses trabalhadores. Sobre isso, Gilberto se recorda de um episódio de que foi vítima de uma agressão verbal:

[Um dia] uma senhora de Corolla veio e bateu [em mim]. E eu [estava] parado. [...] Eu olhei para ela e falei: "Minha senhora, a senhora não me viu aqui? A senhora bateu na minha perna, podia ter acontecido uma coisa pior?". Ela abaixou o vidro, falando no celular e falou um monte de palavrão. É inacreditável. [...] Eu fiquei doido com ela. Eu falei: "Minha senhora, a senhora é doida?". Aí, os motoqueiros que estavam [perto de mim], [...] viram aquilo e eles ficaram bravos. Eu não precisei tomar atitude nenhuma. [...] Cada um que passava dava um chute. (Gilberto, motofretista, 2010)

0 mesmo depoente dá um testemunho sobre a inimizade que vem se naturalizando entre caminhoneiros e motofretista, que fornece mais elementos para se analisar os reflexos da reificação do ser social sobre as relações que se estabelecem no espaço urbano:

Hoje eu trabalho com caminhão e ouço muito os caminhoneiros [dizerem] [...]: "Eu esqueci o meu gancho de pegar motoqueiro lá em São Paulo". Então assim, [os "motoboys"], eles são muitos, quem dirige em São Paulo vê como eles passam buzinando, desesperados para fazer um trabalho que não é deles, para cumprir uma ordem de estar ali, para cumprir um horário, às vezes não é imprudência dele, ele tem que fazer o serviço dentro do horário ou ele está fora. (Gilberto, motofretista, 2010)

0 relato acima aponta, não só para 0 espectro de hostilidade que ronda as relações sociais no trânsito das cidades, mas também para a subsunção desse espaço de circulação do capital, em que se constitui a malha viária, ao tempo e ritmo impostos pela acumulação flexível, caracterizada pelo ideário da produção just in time. 0 depoimento mostra a subversão total do controle do tempo a que os motofretistas estão submetidos, "um tempo que não é seu", um ritmo que lhe é determinado seguir.

Esse sentimento de um tempo irrefreável, de um ritmo que não se pode conter, que de certo modo está presente na experiência subjetiva de todos os seres humanos da contemporaneidade, traduz de modo preciso a vida objetiva desses trabalhadores sobre duas rodas, mergulhados no processo contraditório de fabricalização das cidades. Esse processo de fabricalização se constitui, de acordo com Ferrari (2012), em um extravasamento do modo de trabalho dos antigos lugares específicos de produção com vistas a imprimir um ritmo acelerado a todos os contextos sociais e territoriais que compõem o espaço ampliado da produção just in time:

0 timing necessário e específico ao capital como relação social hegemônica não é imposto apenas no chão de fábrica, ou na suposta loucura das bolsas de valores. A circulação de coisas, pessoas e informações no cotidiano das grandes cidades impõe um ritmo intenso a todos, trabalhem ou não no chão de fábrica, escritórios ou bolsas de valores. Os tempos exigidos para um motoboy entregar um documento, para se desenvolver uma tese acadêmica 
ou formar alunos no ensino fundamental, médio e universitário são continuamente comprimidos. (Ferrari, 2012, p. 37)

Esse extravasamento da produção just in time para toda a sociedade, que define o processo de fabricalização das cidades, deve-se, por sua vez, ao atendimento das necessidades atuais da dinâmica do capital. Após a reestruturação produtiva ter reformulado o processo produtivo do lado de dentro dos muros da fábrica, para sua plena execução fez-se necessário que outras instâncias se sincronizassem a esse tempo tido como certo, como, por exemplo, os fornecedores terceirizados localizados fora das unidades fabris e toda a malha viária das cidades que se transformou em extensão da linha de montagem dessa fábrica supostamente enxuta, limpa e silenciosa, idealizada pelo toyotismo (ibid.).

Ou seja, a despeito do discurso ideológico, que engraxa a engrenagem dessa produção "flexível", sustentar-se na idealização de uma produção essencialmente imaterial e em tempo real, conforme afirmam os ideólogos de uma concepção de sociedade da informação que prescinde do trabalho:

Sabemos que, pelo menos por enquanto, pessoas, cachorros, automóveis e outros valores de uso não trafegam por fibras óticas. [...] Caminhões, automóveis e motos existem de modo presencial, não virtual, transitam em espaços físicos (não em fibras óticas), percorrem vias em tempo material não nulo, além de transportarem mercadorias que, para serem produzidas, ocuparam também tempos de produção e espaços concretos, materiais [...]. (Ibid., p. 48)
Desse modo, na medida em que a produção e reprodução da vida material da sociedade não prescindem da sua materialidade no espaço e no tempo, o conjunto de meios de racionalização e sincronização de tempos de trabalho e fluxos de mercadorias, que se constituiu no componente técnico-organizacional do ideário toyotista de uma produção sem estoque e no tempo certo, implicou a transferência do ônus das operações logísticas para a sociedade civil e seu poder local. Segundo Ferrari (ibid., pp. 42-43):

Na era dourada do capital, as cidades sediavam fábricas consideradas lugares relativamente à parte; hoje, tornaram-se espaços de estoques das mercadorias em trânsito, receptáculos de verdadeiras esteiras fordistas estendidas entre as fábricas. Ao contrário de serem sóbrias, limpas ou de serviços, são cidades fabricalizadas, que acolhem atividades de todo tipo como extensões urbanas da própria fábrica, acolhendo um imenso proletariado urbano que cada vez mais se multiplica e se fragmenta.

Com o extravasamento da produção para além dos muros das fábricas tratou-se, portanto, de socializar os custos da gestão do caos dos tempos e dos espaços urbanos. Desse modo, a aparente desordem que domina o cenário urbano é a ordem do capital na contemporaneidade, é a ordem da cidade fabricalizada (ibid., 2012).

Nesse sentido, a hostilidade que permeia a vida social nos espaços públicos da cidade e que atinge tão diretamente os motofretistas, na forma de ameaça física e psíquica permanentemente enfrentada em seu processo de 
trabalho, não pode ser explicada sem se levar em consideração essa determinação objetiva da atual forma de ser do modo de produção e reprodução social do capital.

Além desses testemunhos acima analisados em que os motofretistas figuraram como vítima de agressões de outros condutores de veículos, muitas vezes a situação se inverte, e o motofretista aparece como o agressor, impulsionado por essa sociabilidade urbana marcada pela hostilidade, conforme mostra o relato abaixo:

Esses tempos atrás eu fiquei com dó do cara, mas ao mesmo tempo eu fiquei com raiva dele, eu quebrei o retrovisor dele, ali na Bambini. Eu estava com pressa para fazer o serviço, isso já era quase seis horas da tarde. Eu precisava fazer, devolver ao Banco para sair e voltar para casa. Aí eu vi que ele me viu no retrovisor, [...] [mas] na hora que ele viu que eu ia encostar, ele me fechou. Aí não teve jeito, pus os dois pés na frente e acelerei a moto. Ao invés de eu parar a moto, eu acelerei. 0 pior é que eu quebrei o retrovisor dele e de um coitado que estava no lado que não tinha nada a ver, então me deu dó do rapaz que estava do lado. Na cabeça eu fiquei pensando, porque ele fez isso? Pra quê? Eu estou trabalhando! Não estou me divertindo, isso não é uma diversão. Talvez o cara pensa que é diversão. É uma profissão igual a todas as outras. (José, motofretista, 2010)

Assim, o sentimento de irritação e cansaço que resulta da vivência desse ambiente de hostilidade e do frequente risco que os motofretistas correm ao terem que disputar as ruas da cidade com os carros, ônibus, peruas, caminhões, em condições completamente desfavoráveis ao respeito mútuo, apresentou-se como um aspecto marcante da experiência deles, como um fator de doença física e psíquica, como fator de sofrimento.

Esse tipo de constrangimento com vistas a intensificar o trabalho não se constitui, todavia, em uma particularidade vivenciada individualmente pelos trabalhadores entrevistados, mas se trata de um aspecto geral da organização do trabalho nos espaços de circulação da cidade fabricalizada, conforme atenta Ferrari:

Para realizarem as entregas no almejado tempo certo e manterem a continuidade do fluxo da produção, trabalhadores viário e rodoviário de carga, por exemplo, enfrentam toda sorte de obstáculos. Além de intensificação do trabalho pelo aumento do número de viagens/dia, esses trabalhadores chegam a ser pessoalmente penalizados com multas por atrasos - racionalidade interiorizada e justificada como garantia de eficácia do processo produtivo. [...] A adoção atual do lema "tempo é dinheiro" resulta na compressão do espaço pelo tempo. (Ibid. p. 27)

Esse cenário descrito acima por Ferrari aparece, por sua vez, exemplarmente retratado no relato de um entrevistado do estudo que comenta sobre o desgaste que sente em sua profissão:

É estressante! E é complicado por causa disso, porque há cobrança. Porque hoje em dia, infelizmente, se [você] pega três serviços para fazer e pergunta qual é mais urgente. Vão te responder: "Todos, todos são urgentes!". Todo mundo hoje tem pressa, porque o tempo, hoje em dia, nada mais é que dinheiro! (Paulo, motofretista, 2010)

Esse relato deixa claro que, se o ritmo acelerado da atividade de motofrete é uma decorrência da própria dinâmica atual do 
processo de reprodução ampliada do capital, na conjuntura da subsunção do espaço ampliado da produção ao ideário do just in time, o risco de morte a que os motofretistas estão submetidos é consequência direta da pressão exercida pela organização do trabalho para a execução do trabalho numa cadência sincronizada a um tempo definido como certo, a cadência da realização da mais-valia dentro da atual dinâmica da acumulação.

Por fim, cabe chamar a atenção para o fato de que, ainda que a morte não seja um desfecho obrigatório dessas trajetórias de trabalho na cidade fabricalizada, diante dessa conjuntura de pressão da organização do trabalho, somada ao espectro de hostilidade e violência que, de modo geral, permeia a sociabilidade urbana, o resultado não poderia ser outro para aqueles que passam aproximadamente 15 horas de seu dia sobre uma motocicleta: memórias de muitos acidentes, vividos ou assistidos, corpos e mentes, marcada intensificação do trabalho.

Então, é nesse jogo arriscado de desafiar o perigo, no limite entre a vida e a morte, que esses homens e mulheres vêm realizando o seu trabalho, numa sincronização alienante ao tempo exigido pela produção just in time. Desse modo, a cidade que "se assimila - e se desenvolve, contraditoriamente, na medida de um tempo real tornado expressão mítica das sociedades contemporâneas" (Ferrari, 2012, p. 37), produz efeitos psíquicos devastadores, que podem ser sentidos, não só por essa categoria profissional, mas por tantas outras que estão submetidas ao mesmo processo de compressão dos intervalos de tempo, tais como os operadores de telemarketing, os bancários, os caminhoneiros, os corretores de bolsa, etc.
Como consequência dessa mudança estrutural na experiência temporal, uma nova subjetividade precisa ser moldada. 0 novo tipo de consentimento construído pelo toyotismo pressupõe uma sociedade com indivíduos condicionados a permanecer em sincronia constante com esses ritmos de trabalho (ibid.). Conforma, portanto, um novo tipo de subjetividade moldada pela máxima: Right man in the rigth place, on the right time, a qual é caricaturalmente representada nas exigências feitas aos motofretistas na contemporaneidade.

Para explicar essa dimensão da produção just in time que se transborda para a vida interior do sujeito, Alves (2005) cunha um conceito que contribui para o entendimento do desgaste psíquico que decorre das condições de trabalho enfrentadas nas cidades fabricalizadas. Em uma reflexão sobre o impacto da compressão do tempo e do espaço na organização do tráfego corpo-mente, o autor refere-se a um processo de "compressão psicocorporal", como uma forma de moldagem do corpo rígido do taylorismo-fordismo, para a flexibilidade do toyotismo, mantendo, ao mesmo tempo, esse corpo útil ao novo modo de produção e alargando o raio de ação do sofrimento do trabalho por meio de seu deslocamento para a mente.

Assim, buscando aprofundar o entendimento desse mecanismo de "compressão psicocorporal", é importante chamar a atenção para os dois elementos ontológicos que compõem esse binômio sugerido no conceito, corpo e psique. 0 corpo, "elemento ineliminável do sujeito" (ibid.), pressupõe uma materialidade que ocupa lugar no espaço. Por sua vez, o tempo é a "a condição ontológica do psiquismo" (Kehl, 2009). 
Desse modo, 0 acirramento da compressão do espaço pelo tempo não poderia deixar de ter impactos acentuados sobre a vida psíquica dos sujeitos, como mostram não só os relatos dos trabalhadores entrevistados, como também a própria epidemia social de depressão e outras formas de mal-estar emocional da civilização contemporânea. A organização toyotista da produção e da vida social amplia o sofrimento para a mente, uma vez que abala justamente a qualidade da experiência do tempo. De acordo com a análise de Kehl acerca da depressão na contemporaneidade:

[...] é razoável supor uma relação entre o aumento dos casos de depressão e a urgência que a vida social imprime à experiência subjetiva do tempo. A temporalidade tecida de uma sequência de instantes que comandam sucessivos impulsos à ação, não sustentados pelo saber que advém de uma prévia experiência de duração, é uma temporalidade vazia, na qual nada se cria e da qual não se conserva nenhuma lembrança significativa capaz de conferir valor ao vivido. (2009, p. 116)

Ou seja, na medida em que essa temporalidade contemporânea, vivida como pura pressa, atropela a duração necessária para o exercício do compreender, é possível se ter a dimensão do sofrimento que a exigência de execução das tarefas no menor tempo causa sobre os motofretistas, impulsionando-lhes para a morte, do corpo e da mente. Segundo Kehl:

[...] mal nos damos conta dela, a banal velocidade da vida, até que algum mau encontro venha revelar a sua face mortífera. Mortífera não apenas contra a vida do corpo, em casos extremos, mas também contra a delicadeza inegociável da vida psíquica. (Ibid., pp. 16-17)
Diante da imersão de toda a sociedade nessa relação brutal com o tempo, que promove um processo de banalização da morte no seu sentido mais abrangente, os motofretistas buscam, na solidariedade entre seus iguais, um refúgio. Os inúmeros episódios de mútuo socorro em situações de acidentes ou conflitos no trânsito, que são tão característicos da experiência de classe dessa categoria, constituem-se, portanto, numa resposta a esse cenário de insegurança, solidão e sofrimento psíquico que aflige de modo muito intenso esses trabalhadores.

Desse modo, a atitude corporativa, e por vezes agressiva, dos motofretistas em seus enfrentamentos nas trincheiras da cidade, que incomoda a sociedade e indigna a opinião pública, deve ser entendida como uma compensação psíquica necessária para suportar viver um tempo que autodisciplina o corpo e o espírito para o consentimento ao próprio sofrimento, que fragmenta a luta política em busca de meIhores condições de trabalho e que, sobretudo, corrói o tempo, o "tecido da vida", 7 do qual depende a qualidade do tráfego corpo-mente.

Assim, trata-se de compreender que essa experiência de aceleração do tempo, que influenciou o próprio desenvolvimento da atividade de motofrete, delimitou não apenas uma mudança técnica ou econômica na forma de produção e circulação de mercadorias, mas implicou, sobretudo, uma nova tessitura da vida social e psíquica, que produziu desdobramentos profundos de ordem cultural.

A transformação do tempo em velocidade e do espaço em simples meio de circulação produziu uma experiência social marcada pelo "apagamento de milhares de percepções instantâneas às quais nos limitamos a reagir 
rapidamente para em seguida, com igual rapidez, esquecê-las" (Kehl, 2009, p.17). Assim, imersos no torpor da vida cotidiana, ainda que o encontro com um acidente de trânsito envolvendo um motoqueiro ou o reconhecimento do sofrimento emocional de um entregador que se perdeu no transporte de sua mercadoria despertem, no exato momento, algum sentimento de compaixão e identificação, no instante seguinte será esquecido pela sequência irrefreável de intervalos de tempo vazio.

Os motofretistas interpelam, portanto, sentimentos de inveja pela sua capacidade de fluir pelo caos urbano como ninguém consegue e de indignação pela sua falta de compostura social ao realizar o tempo definido como o certo. Mas seu modo de ser e de agir provoca a sociedade, sobretudo, porque a "loucura" de sua pressa aponta o dedo para a "loucura" que é de todos, ou seja, coloca todos os indivíduos na posição incômoda de ter que se defrontar com a feiura e a brutalidade de sua relação com o tempo, com o espaço e com a vida social.

Ademais, a experiência de violência nesse contexto histórico em que se dá a formação da categoria motoboy e que é partilhado por todos nós na experiência urbana, é uma experiência de violação de direitos individuais ou civis de grande extensão. A violência urbana analisada por Caldeiras (2000), manifesta-se sobre os corpos de cada um (não só dos motoboys) e produz certo tipo de "corpo político", o "corpo não circunscrito". A nossa "democracia disjuntiva", em que se expandem direitos políticos e sociais enquanto se desrespeitam direitos civis e humanos, corpos simbólicos são eleitos como a essência do mal. Os motoboys, no cenário da "cidade fabricalizada", vêm operando esse tipo de mecanismo simbólico. Ao simbolizar todo o estresse da vida urbana na "cidade fabricalizada", permite-se que uma determinada mentalidade se perpetue. A concepção metódica, racional e disciplinada de vida que Max Weber considerou a alavanca principal do capitalismo, metamorfoseou-se em uma forma de dominação legitima sobre os corpos que disciplina, otimiza seus movimentos, reprime e viola direitos civis e humanos.

\section{Considerações finais}

Este escrito buscou reconstruir o longo período histórico de constituição e crise da vida citadina, em duas importantes metrópoles do sudeste brasileiro (RMSP, RMC), erguidas sobre os interesses de mercado das corporações do automóvel, desde a sua implementação em território nacional no contexto do padrão de produção taylorista-fordista até a sua adequação ao ideário da produção just in time. Tratou-se, desse modo, de uma análise da forma de ser-estar dos espaços de circulação da cidade a partir da experiência de duas categorias de trabalhadores que foram capazes de representar os elementos contraditórios da sociabilidade no Brasil que se pretendeu moderno: os metalúrgicos e os motofretistas.

Para além de uma história da cidade, os acontecimentos vivenciados e relembrados pelos sujeitos dessa história, apesar de dispersos no tempo e no espaço, integraram-se, permitindo apreender o processo de formação da classe trabalhadora urbana brasileira, para o qual as migrações se constituíram em ingrediente demográfico e cultural fundamental. Por sua vez, ao voltar-se para as experiências recentes de trabalho dos motofretistas, observou-se 
também que grande parte desses trabalhadores sobre duas rodas tem um passado migratório, de tal forma que a noção de que o desenvolvimento urbano-industrial não pode ser explicado sem considerar as migrações, defendidas por Hobsbawm (2000), foi reforçada.

Debruçando-se sobre a experiência desses que realizam o transporte de mercadorias e documentos utilizando suas motocicletas, percorrendo os espaços de circulação das cidades em um contexto em que a mobilidade urbana é permanentemente ameaçada pelo inchaço da frota de veículos, foi possível refletir sobre as repercussões de longo prazo do processo de modernização capitalista dentro de uma economia dependente, reverente aos interesses de mercado das grandes corporações, tais como a indústria automotiva.
Nesse sentido, na condição de elos da produção capitalista cindida pela reestruturação produtiva, que externalizou parte da produção em nome de um ideário de fábrica enxuta, limpa e silenciosa, esses trabalhadores sobre duas rodas asseguram a atual logística da acumulação, caracterizada pelo processo de compressão do espaço pelo tempo. Seu papel social é, acima de tudo, viabilizar a aceleração do processo de produção-distribuição-troca-consumo. Assim, o que se espera deles é velocidade e, por isso, eles têm pressa. Portanto, seu modo de trabalho é a caricatura, frequentemente renegada pela sociedade, de uma sociabilidade hostil e desgastante, fundada na sincronização alienante ao tempo, cada vez mais curto, da realização da mais-valia.

\section{Stela Cristina Godoi}

Pontifícia Universidade Católica de Campinas, Faculdade de Ciências Sociais. Campinas, SP/Brasil. stela_godoi@yahoo.com.br

\section{Notas}

(1) "A ideia de sociologia é contemporânea da ideia de modernidade. Ambas nascem na cidade. Formam-se principalmente em Paris, capital do século XIX, em meados daquele século. Aí se decantavam as mais novas e típicas realizações materiais e espirituais da sociedade moderna." (lanni, 1989, p. 7)

(2) “A centralização política do Estado inglês tinha fundamentos materiais e corolários. Primeiro, já no século XVI, a Inglaterra possuía uma rede impressionante de estradas e de vias de transportes fluviais e marítimas que unificavam a nação de modo bastante excepcional para o período. Londres cresceu numa taxa muito acima das outras cidades inglesas e do crescimento total da população (transformou-se na maior cidade da Europa) e tornou-se o centro de um mercado nacional em desenvolvimento". (Wood, 2000, p. 9) 
(3) Thompson (2001) utiliza essa expressão no artigo "A história vista de baixo", extraído de The Times Literary Supplement, de 7 de abril de 1966, traduzido por Antonio Luigi Negro e reunido na coletânea de textos de Thompson organizada por Antonio Luigi Negro e Sergio Silva, intitulada As peculiaridades dos ingleses e outros artigos.

(4) Esse estudo, que resultou na dissertação de mestrado intitulada $A$ roça e o aço: as experiências e as resistências operárias no Brasil Moderno (1954-1964), foi desenvolvido a partir da metodologia da história oral, por meio da qual foram coletadas memórias de homens que migraram das zonas rurais do País para empregar-se nas indústrias da cadeia produtiva de automóveis na condição de metalúrgicos. Desse modo, por meio desse processo mnemônico, tratou-se de analisar as experiências desses trabalhadores e as formas de resistência cotidianas forjadas por eles no amálgama cultural do mundo da roça do qual partiram e do mundo do aço no qual ingressaram, colocando em relevo as contradições da cidade erguida sob o ideário da ordem, do progresso e da soberania (Godoi, 2007).

(5) Esse estudo, que resultou na tese de doutorado No tempo certo, sobre duas rodas, um estudo sobre a formação e a exploração dos(as) motofretistas de Campinas-SP, dedicou-se a analisar o processo de trabalho desses trabalhadores que se constituem hoje numa engrenagem fundamental da acumulação capitalista regida pelo ideário da produção just in time, sobretudo considerando o contexto de crise de mobilidade urbana que resultou do consumo em massa de automóveis produzida pela força de mercado assumida por essas corporações no Brasil. Através da análise das experiências de alguns motofretistas e de uma única motofretista, foram apreendidas algumas determinações do processo de formação dessa categoria profissional em Campinas, bem como foram compreendidos os traços mais marcantes que caracterizam a forma de ser da exploração dessa força de trabalho e de dominação desses trabalhadores (Godoi, 2012).

(6) De acordo com Marx (1984), o tempo de produção associado ao tempo de circulação forma o conceito de "tempo de giro do capital" que é de extrema importância para o processo de acumulação.

(7) Essa expressão metafórica para o tempo foi retirada da análise de Kehl (2009), ao parafrasear Antônio Candido, para quem o tempo é o "tecido da nossa vida" (p. 111).

\section{Referências}

ALVES, G. (2005). Trabalho, corpo e subjetividade: Toyotismo e formas de precariedade no capitalismo global. Trabalho, Educação e Saúde. Rio de Janeiro, v. 3, n. 2, pp. 409-428.

BENJAMIN, W. (1994). "Sobre o conceito de História". In: BENJAMIN, W. Magia e técnica, arte e política: ensaios sobre literatura e história da cultura. São Paulo, Brasiliense (Obras escolhidas, v. 1), pp. 222-234.

(s/d). "Paris, capital do século XIX". In: KOTHE, F. R. (org.); FERNANDES, F. (coord.). Walter Benjamin. Sociologia. São Paulo, Ática (Coleção Grandes Cientistas Sociais, n. 50), pp. 30-43.

CALDEIRAS, T. P. do R. (2000). Cidade de muros: crime, segregação e cidadania em São Paulo. São Paulo, Ed. 34 e Edusp. 
CERTEAU, M. (1994). A invenção do cotidiano: 1. Artes de fazer. Petrópolis/RJ, Vozes.

FERRARI, T. (2012). Fabricalização da cidade e ideologia da circulação. São Paulo, Outras Expressões.

FONTES, P. R. R. (2004). “Migração Nordestina e experiências operárias: São Miguel Paulista nos anos 1950". In: BATALHA, C. M. et al. (orgs.). Culturas de classe: identidade e diversidade na formação do operariado. Campinas, Ed. Unicamp.

GODOI, S. C. (2007). A roça e o aço: as experiências e as resistências operárias no Brasil Moderno (1954 a 1964). Dissertação de Mestrado. Campinas,Universidade Estadual de Campinas.

(2012). No tempo certo, sobre duas rodas: um estudo sobre a formação e a exploração dos(as) motofretistas de Campinas-SP. Tese de Doutorado. Campinas, Universidade Estadual de Campinas.

HADLER, M. S. (2007). Trilhos de modernidade: memórias e educação urbana dos sentidos. Tese de Doutorado. Campinas, Universidade Estadual de Campinas.

HARVEY, D. (2014). Cidades Rebeldes. Do direito à cidade à Revolução urbana. São Paulo, Martins Fontes.

HOBSBAWM, E. J. (2000). “Qual é o país dos trabalhadores?”.In: HOBSBAWM, E. J. Mundos do trabalho. Novos estudos sobre História Operária. São Paulo, Paz e Terra.

IANNI, O. (1989). A sociologia e o mundo moderno. Tempo Social, v.1, n. 1, pp. 7-27.

(1992). A ideia de Brasil Moderno. São Paulo, Brasiliense.

KEHL, M. R. (2009). O tempo e o cão: a atualidade das depressões. São Paulo, Boitempo.

KURZ, R. (1996). Luz verde para o caos da crise. Cadernos do Labur. São Paulo, ano I, n. 1 (Série Autores Alemães).

LÖWY, M. (2005). Walter Benjamin: Aviso de incêndio: uma leitura das teses "Sobre o conceito de história". São Paulo,Boitempo, 160p.

MAPA DA VIOLÊNCIA 2011: Os jovens do Brasil. Caderno Complementar Acidentes de Trânsito. Disponível em: www.mapadaviolencia.org.br. Acesso em: set 2012.

MARTINS, J de S. (2000). A sociabilidade do homem simples. São Paulo, Hucitec.

(2004). “O migrante brasileiro na São Paulo estrangeira”. In: PORTA, P. (org.). História da cidade de São Paulo, v. 3: a cidade na primeira metade do século XX. São Paulo, Paz e Terra.

MARX, K. (1984). O Capital: crítica de economia política. Livro Segundo. São Paulo, Abril Cultural, 2 v. (Os economistas).

PINTO, G A. (2006). "Uma introdução à indústria automotiva no Brasil”. In: ANTUNES, R. (org.). Riqueza e miséria do trabalho no Brasil. São Paulo, Boitempo.

RIBEIRO, D. (1995). O povo brasileiro: evolução e sentido do Brasil. São Paulo, Companhia das Letras.

SANTOS, M. (1979). Economia espacial. Críticas e alternativas. São Paulo, Hucitec.

SILVA, M. A. de M. (2005). “Contribuições metodológica para a análise das migrações” In: DEMARTINI, Z. de B. F. (org.). Estudos migratórios: perspectivas metodológicas. São Carlos, EdUFSCar.

SILVEIRA, P. (1989). "Da alienação ao fetichismo - formas de subjetivação e de objetivação". In: SILVEIRA, P. e DORAY, B. (orgs.). Elementos para uma teoria marxista da subjetividade. São Paulo, Vértice; Revista dos Tribunais. 
TELLES, V. S. (2006). Mutações do trabalho e experiência urbana. Tempo Social, revista de sociologia da USP, v. 18, n. 1, pp. 173-195.

THOMPSON, E. P. (1981). A miséria da teoria: um planetário de erros. Rio de Janeiro, Zahar.

(1987). “Prefácio. Agosto de 1963” In: THOMPSON, E. P. A formação da classe operária inglesa. Rio de Janeiro, Paz e Terra.

(2001). "A História vista de baixo". In: THOMPSON, E. P. As peculiaridades dos ingleses e outros artigos. Campinas, Editora da Unicamp.

WOOD, E. M. (2000). As origens agrárias do capitalismo. Revista Crítica Marxista. São Paulo, n. 10.

Texto recebido em 15/jan/2016

Texto aprovado em 29/fev/2016 
